Article

\title{
Elderly's Travel Patterns and Trends: The Empirical Analysis of Beijing
}

\author{
Wenzhi Liu ${ }^{1,2}$, Huapu Lu ${ }^{1, *}$, Zhiyuan Sun ${ }^{3}$ and Jing Liu ${ }^{1}$ \\ 1 Institute of Transportation Engineering, Tsinghua University, Beijing 100084, China; \\ liuwenzhi@buu.edu.cn (W.L.); liujing14@mails.tsinghua.edu.cn (J.L.) \\ 2 Department of Management, Beijing Union University, Beijing 100101, China \\ 3 College of Metropolitan Transportation, Beijing University of Technology, Beijing 100124, China; \\ sunzhiyuan@bjut.edu.cn \\ * Correspondence: luhp@mail.tsinghua.edu.cn
}

Academic Editor: Tan Yigitcanlar

Received: 24 April 2017; Accepted: 5 June 2017; Published: 7 June 2017

\begin{abstract}
Travel by the elderly is generally characterized by relatively short distances and low frequencies. However, with social development, the travel patterns of the elderly are lacking in sustainability. In some European countries, the elderly are increasingly dependent on cars while traveling. In addition, the influencing factors of the elderly's travel behavior are also changing. At present, most foreign and domestic studies focus on the impact of individual and household socioeconomic attributes, travel attributes, and policy factors on the travel frequency, travel mode choice, and travel demand of the elderly, but they lack an analysis of the regional differences of the elderly's travel behavior characteristics and related countermeasures. The studies excessively focus on the influencing factors but overlook the difference between the elderly's travel characteristics and young people's travel characteristics, as well as the interactions at the household level. Based on data from the Fifth Travel Survey of Residents in Beijing 2014, this paper uses variance analysis, Spearman's correlation analysis, and descriptive and comparative analysis to study the difference in travel frequency over 24 hours between the elderly and middle-aged/young people in Beijing, the impact of household, individual, and travel attributes on the travel frequency difference, and the regional difference in the elderly's travel behavior characteristics. The results show that there is a significant difference in travel frequency between the elderly group and the middle-aged/young group in Beijing; the main reason is the individual difference between travelers. Travelers' attributes all exert an influence on the travel frequency of both groups, but the degree and direction of the influence are different. At the household level, middle-aged/young people with a higher household income travel less frequently, whereas the case is completely the opposite for the elderly. In terms of personal attributes, gender has a significant negative effect on the elderly's travel frequency; that is, women travel less than men, whereas there is no difference between men and women in middle-aged/young people. Regarding travel attributes, travel distance and travel duration have a significant negative effect on the two groups' travel frequencies. The elderly in some European countries are more dependent on cars, whereas a large proportion of elderly people in Beijing walk on foot, but the degree of dependence on cars of the "new generation" of the elderly in Beijing will increase rapidly, which will bring the lack of sustainability of travel patterns, further bringing new challenges to policymakers and transport planning departments.
\end{abstract}

Keywords: elderly; mobility; sustainability; frequency; Beijing 


\section{Introduction}

The aging of the population is a significant social challenge that the world is facing. Some studies predict that, by 2050, the proportion of the elderly population aged 60 and over will reach $34 \%$, from $16.1 \%$ in 2015, in China, and reach $42.5 \%$, from $32.7 \%$ in 2015, in Japan; the proportion of the elderly population aged 65 and over will reach $20.9 \%$, from 13.1\% in 2010, in the United States [1-3]. As people age, physiological and psychological changes occur [4]. Therefore, in addition to its social and economic impact, the phenomenon of aging also brings a significant effect on people's mobility [5]. Regardless of country, travel by the elderly is generally characterized by relatively short distances and low frequencies [6]. However, with global economic, scientific, and technological development and medical advances, the elderly's lifestyle is constantly changing and their mobility pattern is lacking in sustainability, resulting in changes in their travel characteristics: (1) compared to the past, the elderly's travel demand continues to show a growth trend; (2) studies in some European countries have found that the elderly are more likely to rely on cars than in the past; and (3) compared to young people, the elderly's travel characteristics and influencing factors are also changing [7-9]. At present, most foreign and domestic studies focus on the impact of individual and household socioeconomic attributes, travel attributes, and policy factors on travel frequency, travel mode choice, and travel demand of the elderly [8-10]. Meanwhile, several studies have highlighted that the increased travel demand and mobility of the elderly exacerbate traffic congestion, environmental pollution, and health problems [11].

Although the above studies provide a basis for research in this field, some shortcomings remain. (1) Although the elderly's travel demand and car dependency are increasing, their travel behavior characteristics, such as the degree of mobility and household structure, are very different due to the different levels of economic development in different countries and regions; therefore, the government should adopt travel demand management policies and measures "according to local conditions". (2) Although some studies have compared the behavioral characteristics of the elderly and the non-elderly, the research vision and method are relatively simple; most studies are only a descriptive and comparative analysis and lack a statistical analysis and statistical reference of the sample data; other studies have only compared and analyzed the differences between the influencing factors of the two groups rather than the travel characteristics of the two groups. (3) Most previous studies have used traffic log-based travel chain data, but the travel data of the elderly in developed countries often lack the effects of interactions at the household level due to the different lifestyles of elderly people in different countries and regions; for example, the average household size of the elderly aged 65 and above in Rotterdam, the Netherlands, in 2014 was 1.7, meaning that most of the elderly do not live with their children, whereas the average household size of the elderly aged 60 and above in Beijing in 2014 was 2.9, meaning that the household includes children who live with elderly couples [12].

Based on the above-mentioned shortcomings, this paper studies the difference in travel frequency over 24 hours between the elderly and the middle-aged/young in Beijing, as well as the influence of household, individual, and travel attributes of travelers on their difference in travel frequency; it also compares travel characteristics between the elderly in Beijing and the elderly in developed areas of some other countries.

\section{Literature Review}

In the research field of the elderly's travel demand characteristics such as travel frequency and travel mode choice, it is generally considered that the elderly's travel shows the characteristics of "relatively short distances and low frequencies" $[1,2,6,8]$. Specifically, the current domestic and international research is focused on the following aspects.

In terms of the influencing factors of the elderly's travel behavior characteristics, most studies take three aspects: individual attributes, household attributes, and travel attributes. In recent years, studies have begun to add the factor of season and explore its impact on the elderly's travel behavior. 
Regarding individual attributes, existing studies have demonstrated that gender, employment status, driver's license, educational level, and ethnicity have significant effects on senior citizens' travel behavior [13-16]. Some studies have suggested that women and the unemployed elderly travel a shorter distance and are less likely to travel and that women are more reliant on public transport [17]. Elderly women from minority groups travel less frequently [18]. The possession of a driver's license has an impact on travel frequency [19]. The elderly with a higher level of education travel more frequently and tend to use public transport [8].

Regarding household attributes, the elderly with a high household income tend to use cars for travel [19]; the elderly with a low household income or the unemployed elderly are more inclined to walk and use bicycles [17]; single elderly people are more inclined to use public transport [17]. Regarding travel attributes, cars are used the most during travels whose purpose is shopping [10]. Regarding the living environment, some studies have noted that the elderly in areas with a high degree of urbanization and a heavy population density show travel characteristics of "short distances, high frequencies, and preferences for public transport" [8]. In the Netherlands, the elderly in the downtown area are more inclined to walk than the elderly in the suburbs [20]; parks, shopping malls, and sidewalks around residential areas have a positive effect on the walking of the elderly [7]. Regarding the factor of season, the elderly use cars more frequently in the winter; a low temperature has a significant negative effect on the elderly's travel by walking and biking [21].

In addition, there are a few other voices in current studies. Although some studies in Europe, such as in the UK and the Netherlands, have shown that the elderly are increasingly dependent on cars, some studies in North America and Australia have revealed a decline in the proportion of car travels among the elderly [9]. Overall, the elderly's travel patterns are changing, they lack sustainability. Some studies have demonstrated that the degree of urbanization has no significant impact on the elderly's recreational travel frequency or travel distance [22]; in turn, some scholars have suggested that the increased mobility level of the elderly has a negative effect on environmental pollution, traffic congestion, and their physical health [23-25].

In the past two years, some scholars have introduced travelers' health factors into research, and a study in Rotterdam, the Netherlands, shows that obesity has no significant impact on the travel frequency of the elderly whereas physical disability has a very strong negative effect on the travel frequency of the elderly [8].

The different levels of economic development and different household structures in different regions often cause very different travel behavior [26,27]. In addition, most of the above studies are only a descriptive analysis and lack an inferential analysis on the sample data. It is very necessary to analyze the elderly's travel behavior characteristics in Beijing. However, the impact of health and weather factors on the elderly's travel characteristics will not be mentioned in this paper due to the lack of data.

\section{Research Design}

\subsection{Research Scope}

The scope of this study is Beijing's urban areas, including the central city area of Beijing (Dongcheng District and Xicheng District) and suburban areas (Chaoyang District, Haidian District, Fengtai District, and Shijingshan District). According to data released by the National Bureau of Statistics of China in 2015, there are 11.717 million residents in Beijing's urban areas, and the population density is up to 8500 per square kilometer. The reasons for choosing this region are as: (1) The population density of the outer suburban areas of Beijing is only over 600 people per square kilometer, which is greatly different from that of urban areas; accordingly, people's behavior characteristics are very different. (2) The population composition of the region is more diverse; there are old local Beijingers in the central downtown area as well as immigrants with different economic and cultural backgrounds. (3) Beijing is facing an enormous challenge due to population aging. By 2014, 
the city had 400 more old people every day. The elderly population over 60 years old had surpassed 3 million, and it is expected to reach 4 million by 2020 and reach its peak in 2055 [1]. The elderly population is mainly distributed in Chaoyang, Haidian, Fengtai, and Xicheng districts.

\subsection{Data}

The data of this study are from the Fifth (2014) Travel Survey of Residents in Beijing. The total sample consisted of 40,000 households, approximately 12 million people between September 2014 and December 2014 in the whole Beijing area. The investigators visited the households twice; during the first visit, they recorded the basic information and left a "traffic $\log$ " for each investigated household, and during the second visit, they conducted interviews and collected the "traffic log".

To balance the distribution of the sample data, the method of stratified sampling is used to randomly extract part of the survey data from the data of Beijing's urban areas. The collected data include three modules: travel information (travel distance, travel purpose, travel destination, travel mode, etc.), household information (household income, floor area, number of household members, number of cars, etc.), and individual information (age, gender, monthly tickets, etc.). According to China's statutory retirement age and the provisions concerning adults, this study defines travelers aged 60 or above as the elderly, and there are 1074 elderly people, accounting for $17.5 \%$ of the total number of study subjects. The study defines travelers $18-59$ years of age as middle-aged/young people; there are 5073 middle-aged/young people, accounting for $82.5 \%$ of the total number of study subjects.

The descriptive statistical results of all sample data are shown below in Tables 1-3.

Table 1. Descriptive statistical results of all sample data (numerical variables).

\begin{tabular}{|c|c|c|c|c|c|}
\hline \multirow{2}{*}{ Variable Classes } & \multirow{2}{*}{ Variable Description } & \multicolumn{2}{|c|}{ Elderly Group } & \multicolumn{2}{|c|}{ Middle-Aged/Young Group } \\
\hline & & Mean & Standard Deviation & Mean & Standard Deviation \\
\hline \multirow{2}{*}{ Travel attributes } & Travel frequency & 2.83 & 1.24 & 2.51 & 1.09 \\
\hline & Travel duration (min) & 28.40 & 27.90 & 39.00 & 37.60 \\
\hline Household attributes & No. of household members & 2.90 & 1.20 & 3.00 & 0.90 \\
\hline Individual attributes & Age & 67.20 & 5.40 & 41.30 & 10.80 \\
\hline
\end{tabular}

Table 2. Descriptive statistical results of the elderly group (classified variables).

\begin{tabular}{|c|c|c|c|c|c|c|c|}
\hline \multirow{2}{*}{ Variable Classes } & \multirow{2}{*}{$\begin{array}{c}\text { Variable } \\
\text { Description }\end{array}$} & \multicolumn{6}{|c|}{ Each Category's Percentage (\%) } \\
\hline & & 0 & 1 & 2 & 3 & 4 & 5 \\
\hline \multirow{2}{*}{ Travel attributes } & Travel purpose & $2.3 \%$ & $0.0 \%$ & $47.7 \%$ & $2.1 \%$ & $5.7 \%$ & $42.2 \%$ \\
\hline & Travel mode & $20.4 \%$ & $14.6 \%$ & $5.2 \%$ & $54.7 \%$ & $0.6 \%$ & $4.5 \%$ \\
\hline \multirow{4}{*}{ Household attributes } & Type of housing & $12.4 \%$ & $5.1 \%$ & $82.5 \%$ & & & \\
\hline & Number of cars & $74.3 \%$ & $24.9 \%$ & $0.8 \%$ & & & \\
\hline & Number of bicycles & $27.6 \%$ & $35.0 \%$ & $37.4 \%$ & & & \\
\hline & Monthly income & $9.5 \%$ & $23.9 \%$ & $24.3 \%$ & $24.2 \%$ & $15.2 \%$ & $2.7 \%$ \\
\hline \multirow{4}{*}{ Individual attributes } & Hhold registration & $7.5 \%$ & $92.5 \%$ & & & & \\
\hline & Employment status & $88.5 \%$ & $11.5 \%$ & & & & \\
\hline & PT monthly tickets & $5.6 \%$ & $94.4 \%$ & & & & \\
\hline & Gender & $53.4 \%$ & $46.6 \%$ & & & & \\
\hline
\end{tabular}

Note: travel purpose $(0=$ work, $1=$ school, $2=$ home, $3=$ business travel, $4=$ shuttle (drop off $/$ pick up), $5=$ others (including shopping, dining, seeing a doctor, visiting friends, entertainment and fitness); travel mode ( $0=$ bicycle, 1 = ground bus, 2 = car, $3=$ walking, 4 = subway, $5=$ others (including taxi, scheduled bus, and motorcycle); monthly income $(0=$ less than 1500, 1 = between 1500 and 2500, 2 = between 2500 and $3500,3=$ between 3500 and 5500, 4 = between 5500 and 10,000, $5=$ more than 10,000); Type of housing $(0=$ one-floor housing; 1 = economically-affordable housing; 2 = commercial residential housing); Number of cars (0: none; 1 : 1 car; 2: $\geq 2$ cars); Number of bicycles (0: none; 1 : 1 bicycle; $2: \geq 2$ bicycles); Household registration $(0=$ non-Beijing registration; $1=$ Beijing registration); PT monthly tickets $(0=$ no, $1=$ yes); Employment status $(0=$ employed, 1 = unemployed, 2 = student $)$; Gender $(0=$ male, $1=$ female $)$. 
Table 3. Descriptive statistical results of the middle-aged/young group (classified variables).

\begin{tabular}{|c|c|c|c|c|c|c|c|}
\hline \multirow{2}{*}{ Variable Classes } & \multirow{2}{*}{ Variable Description } & \multicolumn{6}{|c|}{ Each Category's Percentage (\%) } \\
\hline & & 0 & 1 & 2 & 3 & 4 & 5 \\
\hline \multirow{2}{*}{ Travel attributes } & Travel purpose & $29.0 \%$ & $0.9 \%$ & $45.4 \%$ & $3.1 \%$ & $6.4 \%$ & $15.2 \%$ \\
\hline & Travel mode & $24.9 \%$ & $17.5 \%$ & $29.4 \%$ & $19.9 \%$ & $3.5 \%$ & $4.8 \%$ \\
\hline \multirow{4}{*}{$\begin{array}{l}\text { Household } \\
\text { attributes }\end{array}$} & Type of housing & $20.3 \%$ & $5.0 \%$ & $74.6 \%$ & & & \\
\hline & Number of cars & $56.7 \%$ & $41.9 \%$ & $1.4 \%$ & & & \\
\hline & Number of bicycles & $19.8 \%$ & $36.5 \%$ & $43.6 \%$ & & & \\
\hline & Monthly income & $8.2 \%$ & $16.8 \%$ & $25.4 \%$ & $29.0 \%$ & $17.3 \%$ & $3.3 \%$ \\
\hline \multirow{4}{*}{$\begin{array}{l}\text { Individual } \\
\text { attributes }\end{array}$} & Household registration & $14.2 \%$ & $85.8 \%$ & & & & \\
\hline & Employment status & $85.0 \%$ & $15.0 \%$ & & & & \\
\hline & PT monthly tickets & $71.9 \%$ & $26.3 \%$ & $1.8 \%$ & & & \\
\hline & Gender & $50.4 \%$ & $49.6 \%$ & & & & \\
\hline
\end{tabular}

\section{Methods of Analysis}

\subsection{Procedures of Analysis}

Step 1: We use variance analysis to study the difference in the daily travel frequency over 24 hours between the elderly group and the middle-aged/young group. Since travel frequency is numerical data and being elderly or middle-aged/young is classified data based on age, in this study, variance analysis is more suitable than regression analysis.

Step 2: We use correlation analysis to explore the effect of household, individual, and travel attributes on the travel frequency difference between the elderly and the middle-aged/young.

Accordingly, the procedures and variables of analysis are shown in Figure 1. Some variables from the survey were not used in analysis. The reasons are as follows: (1) Travel frequency is the sum of the trip chain, and each trip has its own transport mode, purpose, and location. It is unable to sum up these three variables because of classified data. (2) The variables that type of housing, number of rooms, floor area, and household registration failed to pass the significance test of relevant analysis.

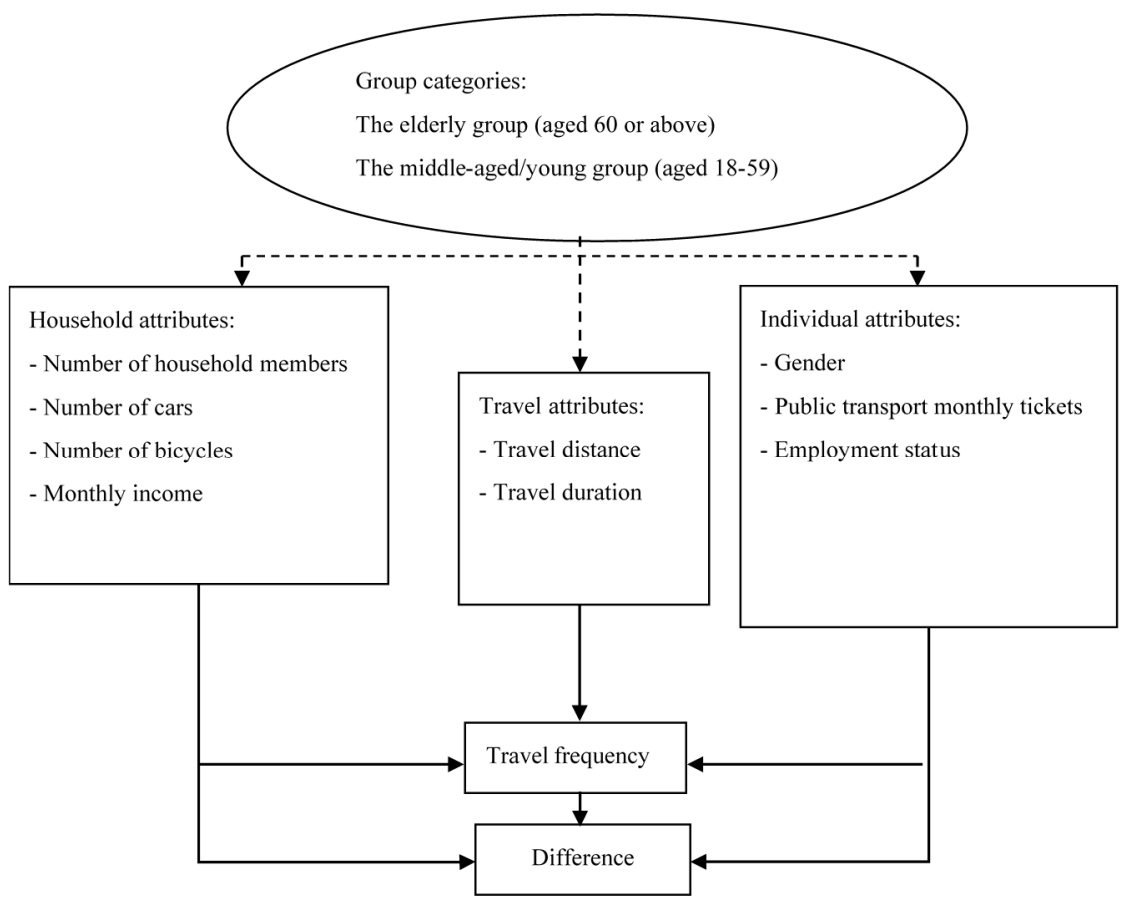

Figure 1. Procedures of analysis. 


\subsection{Difference in Travel Frequency}

Table 1 shows that there is indeed a descriptive difference in travel frequency between the elderly group and the middle-aged/young group. The average travel frequency of the adult middle-aged/young group is 2.51 , whereas the average travel frequency of the elderly group is 2.83 . The elderly group's travel characteristic is "more frequent and shorter in travel distance", which is consistent with the results of previous studies by certain scholars $[1,2,6,8]$.

Furthermore, the total sum of squares (SST) is used in this study to represent the difference between the daily travel frequency and the average travel frequency of each traveler. The difference is composed of two parts: one is the within-group sum of squares (SSWG), representing the individual travel frequency difference, and the other is the between-group sum of squares (SSBG), representing the travel frequency difference between the elderly group and the middle-aged/young group. According to the definition of Pas [28]

$$
\begin{aligned}
\text { SST } & =\sum_{i=1}^{g} \sum_{j=1}^{n_{i}}\left(f_{i j}-\overline{\bar{f}}\right)^{2} \\
S S W G & =\sum_{i=1}^{g} \sum_{j=1}^{n_{i}}\left(f_{i j}-\overline{f_{i}}\right)^{2} \\
\text { SSBG } & =\sum_{i=1}^{g} n_{i}\left(\overline{f_{i}}-\overline{\bar{f}}\right)^{2}
\end{aligned}
$$

where:

- $\mathrm{f}_{\mathrm{ij}}$ is the travel frequency of the $\mathrm{j}$-th individual in the $\mathrm{i}$-th group;

- $\overline{\mathrm{f}_{\mathrm{i}}}$ is the average travel frequency of the $\mathrm{i}$-th group;

- $\quad \overline{\overline{\mathrm{f}}}$ is the average travel frequency of all travelers, that is $\overline{\overline{\mathrm{f}}}=\frac{\sum_{\mathrm{i}=1}^{\mathrm{g}} \sum_{\mathrm{j}=1}^{\mathrm{n}_{\mathrm{i}}} \mathrm{f}_{\mathrm{ij}}}{\mathrm{n}}$;

- $\mathrm{n}$ is the number of all travelers;

- $\mathrm{n}_{\mathrm{i}}$ is the number of travelers in the $\mathrm{i}$-th group; and

- $\mathrm{g}$ is the number of groups, that is, $\mathrm{g}=2$.

In addition, to eliminate the impact of the number of travelers on the degree of difference, we divide the travel frequency difference by its respective degree of freedom and obtain the following:

$$
\begin{aligned}
\text { MSWG } & =\frac{\text { SSWG }}{\mathrm{n}-\mathrm{g}} \\
\text { MSBG } & =\frac{\text { SSBG }}{\mathrm{g}-1}
\end{aligned}
$$

where that MSWG represents the difference in the average travel frequency for individual travelers;

MSBG represents the travel frequency difference between the elderly group and the middle-aged/young group;

- $\mathrm{n}-\mathrm{g}$ is the MSWG's degree of freedom; and

- $\mathrm{g}-1$ is the MSBG's degree of freedom.

Furthermore, the test statistic of the travel frequency difference obtained is as follows:

$$
\mathrm{F}=\frac{\mathrm{SSBG}}{\mathrm{SSWG}}
$$

By comparing the calculated value and the critical value of the F statistic, we can decide the travel frequency difference between the elder group and the middle-aged/young group. 


\subsection{Empirical Analysis of the Travel Frequency Difference}

Even if the elderly group and the middle-aged/young group have significantly different travel frequencies, the difference more frequently results from individuals' travel frequency difference. Therefore, it is necessary to perform an in-depth analysis of the influence of individuals' socioeconomic attributes on the travel frequency characteristics.

In this paper, Spearman's correlation coefficient is used to express the correlation between travelers' socioeconomic attributes and travel frequency. The coefficient $r$ is calculated as follows:

$$
\mathrm{r}=1-\frac{6 \sum \mathrm{d}_{\mathrm{i}}^{2}}{\mathrm{n}\left(\mathrm{n}^{2}-1\right)}
$$

where $\mathrm{n}$ is the number of travelers; and $d_{i}$ is called difference in ranks among the same group $(\mathrm{i}=1,2, \ldots, \mathrm{n})$, which is the difference in the travel frequency and socioeconomic attributes of each traveler. In addition, the significance test statistic of Spearman's correlation coefficient is obtained as follows:

$$
\mathrm{t}=\mathrm{r} \sqrt{\frac{\mathrm{n}-2}{1-\mathrm{r}^{2}}}
$$

By comparing the calculated value and the critical value of the $t$ statistic, we can separately decide the correlation between the travel frequency and individual socioeconomic attributes in the elderly group and the middle-aged/young group.

\section{Result Analysis}

Tables 1-3 show that there is indeed a descriptive difference between the attributes of the elderly group and that of the middle-aged/young group. The proportion of the elderly group without a car is $74.3 \%$, which is much higher than that of the middle-aged/young group. Approximately $5.2 \%$ of the elderly in Beijing travel by car, whereas this proportion is as high as 30\% in middle-aged/young group. The household monthly income of the middle-aged/young group is also significantly higher than the elderly group. The travel attributes of the sample data demonstrate that the average travel distance of the middle-aged/young group is $7 \mathrm{~km}$ and that their average travel duration is $39 \mathrm{~min}$, whereas the average travel distance of the elderly group is $3.2 \mathrm{~km}$, and its average travel duration is $28.4 \mathrm{~min}$. There are also significant differences between the elderly group and the middle-aged/young group in terms of travel purpose. The percentage of travels for "fixed" activities, such as with the purpose of work, in the middle-aged/young group is significantly higher than that in the elderly group, whereas other activities in the elderly group, including household "maintenance" activities and recreational activities with shopping, dining, seeing a doctor, visiting friends, and entertainment and fitness as purposes, have a travel percentage as high as $42.2 \%$, which is far higher than the rate of $15.2 \%$ in the middle-aged/young group.

The analytical results of travel frequency difference by the definition of Pas are shown in Table 4 . That the value of the F statistic is 70.3386 , which is greater than the critical value of 3.842972 , indicating that there is significant difference in travel frequency between the elderly group and the middle-aged/young group. From $R^{2}=1.13 \%$, we can observe that although the travel frequencies of the elderly group and the middle-aged/young group are significantly different, the effect of age on travel frequency is only $1.13 \%$ of the total effect, which means that age has very low explanatory power for the travel frequency difference and that there are many other influencing factors. Based on the calculated SST and SSWG values, the travel frequency of individual travelers varies greatly, accounting for $98.87 \%$. Therefore, it is necessary to perform an in-depth analysis of the influence of individual socioeconomic attributes on travel frequency characteristics. 
Table 4. Analysis of the travel frequency difference.

\begin{tabular}{ccccccc}
\hline Group & Observation Data & Sum & Mean & Variance & & \\
\hline The elderly group & 1074 & 3036 & 2.826 & 1.546 & & \\
The middle-aged/young group & 5073 & 12,746 & 2.512 & 1.180 & & \\
\hline Analysis of difference & & & & & & \\
\hline Source of difference & SS & DF & MS & F & Critical \\
vetween-group & 87.556 & 1 & 87.556 & 70.338 & $6.13 \times 10^{-17}$ & 3.842 \\
Within-group \\
Total
\end{tabular}

Note: significance level of $\mathrm{a}=0.05$.

The analytical results that the effect of household attributes, individual attributes, and travel attributes on the travel frequency difference between the elderly and the middle-aged/young are shown in Table 5. The definition and description of the above variables are shown in Table 1. Both travel distance and travel duration have a significant negative effect on travel frequency, which is in line with the expectation. However, the coefficients are more negative for middle age than for elder. The reason is that the longer travel distance and duration means the more time spend on the way to "work" and back "home" for middle age mainly with "fixed" activities. Thus, there is not enough time to do other activities. Household monthly income significantly affects travel frequency: for the middle-aged/young group, the higher the household income is, the less frequent the travelers travel; the case is completely the opposite for the elderly group. The reason is that middle-aged/young people with a higher household income spend more time on "fixed" activities, namely, longer work hours, which result in less frequent travel. However, the elderly have retired, there are no "fixed" activities for them, and they have a more flexible time allocation. Therefore, the elderly with higher household income spend more time on household "maintenance" activities and recreational activities and, thus, travel more frequently. This finding is consistent with the results of previous studies [23].

Table 5. Influence effects of some key attributes on travel frequency.

\begin{tabular}{ccc}
\hline & The Middle-Aged/Young Group & The Elderly Group \\
\hline Travel distance & $-0.332^{* *}$ & $-0.196^{* *}$ \\
Number of cars & $0.023^{* *}$ & $-0.273^{* *}$ \\
Travel duration & $-0.391^{* *}$ & $0.039^{*}$ \\
Number of bicycles & $0.037^{* *}$ & $0.061^{* *}$ \\
Monthly income & $-0.027^{* *}$ & $0.115^{* *}$ \\
Number of household members & $-0.042^{*}$ \\
Gender & $-0.160^{* *}$ & $-0.038^{*}$ \\
Monthly tickets & $0.090^{* *}$ & \\
Employment status & & \\
\hline Note: ${ }^{* *} p<0.01,^{*} p<0.05$, and a blank space indicates that the variable is not significant.
\end{tabular}

Gender has a significant negative effect on travel frequency in the elderly group; that is, women travel less than men, which is consistent with the results of previous studies [17]. The number of cars has a significant positive effect only on the middle-aged/young group and has no effect on the elderly group. This finding is basically consistent with the descriptive statistics shown in Tables 2 and 3. The number of bicycles has a significant positive effect on the travel frequency of both the elderly group and the middle-aged/young group, which is closely related to the popularity of bicycles in Beijing.

Elderly travelers with more members in the household, that is, a larger household size, have a higher travel frequency. A larger household size means that the elderly must be living with their children, which naturally leads to an increase in travel by the elderly with the purpose of household "maintenance" activities. Household size does not have a significant effect on the travel frequency of middle-aged/young people. 
Since more than $90 \%$ of elderly travelers are unemployed, it is meaningless to study the impact of the variable of employment status on their travel frequency, and this paper does not cover it. However, employment status has a significant positive effect on the travel frequency of middle-aged/young travelers; that is, travelers with no employment have more flexible time, and therefore, their travel frequency increases accordingly.

Monthly tickets have a significant negative effect on the travel frequency of both the elderly group and the middle-aged/young group, which is the opposite of the expected result. After a further descriptive statistical analysis, we find that approximately $80.5 \%$ of middle-aged/young travelers with monthly tickets are with the purpose of "fixed" activities, as "going to work or going home". So their time allocation is relatively fixed, and their travel frequency will not increase with an increase in monthly tickets that they hold. Among elderly travelers with monthly tickets, approximately $90 \%$ of them travel for "other reasons or going home", $52 \%$ have a travel frequency of 2, and $24 \%$ have a travel frequency of 4 . In other words, the majority of travels are focused on "maintenance" activities and recreational activities, the travel time and destination are relatively flexible, but their travel frequency will not increase even if they have more monthly tickets. The reason is that price of PT card is very low with 20RMB (\$3) deposit and average 1RMB $(\$ 0.15)$ for once $[29,30]$.

The comparative data of some attributes of elderly in Beijing and other developed regions are shown in Table 6 [31-33]. The mobility of the elderly in some developed regions is much higher than that of the elderly in Beijing. This finding is partially due to random sampling, but it is more related to the level of regional economic development. At present, the elderly in Beijing mainly travel by walking $(54.7 \%)$ and the rate of household car ownership is very low. However, with the social development, these characteristics will change after a few decades.

Table 6. Comparative data of some attributes of the elderly in some regions.

\begin{tabular}{ccccc}
\hline & $\begin{array}{c}\text { Rate of Household } \\
\text { Car Ownership }\end{array}$ & $\begin{array}{c}\text { Proportion of } \\
\text { Car Mode }\end{array}$ & $\begin{array}{c}\text { Proportion of } \\
\text { Walk Mode }\end{array}$ & $\begin{array}{c}\text { Average Travel } \\
\text { Distance (km) }\end{array}$ \\
\hline Beijing & $25 \%$ & $5.2 \%$ & $54.7 \%$ & 3.2 \\
London & $60 \%$ & $35 \%$ & $24 \%$ & 7.8 \\
New York & $68 \%$ & $89 \%$ & $5 \%$ & 9.1 \\
Rotterdam & $80 \%$ & $40 \%$ & $30 \%$ & 7.5 \\
\hline
\end{tabular}

\section{Conclusions}

With social development, the travel patterns of the elderly are lacking in sustainability. This paper discusses some of the content lacking in current studies on the elderly's travel behavior: (1) an analysis of the regional difference in the elderly's travel behavior characteristics; (2) an analysis of the travel frequency difference between the elderly and the middle-aged/young and its influencing factors; (3) the impact of household size, namely, household-level interactions, on the elderly's travel characteristics; and (4) travel demand management policies and measures due to the lack of sustainability of elderly's travel pattern.

The research results demonstrate the following:

(1) There is indeed a descriptive and inferential significant difference in travel frequency between the elderly group and the middle-aged/young group in Beijing. However, the systematic error of this difference is small, whereas the sample randomness error is large; that is, the travelers are very different. Therefore, it is necessary to analyze the impact of individuals' socioeconomic attributes on travel frequency.

(2) Travelers' household attributes, individual attributes, and travel attributes have an impact on the travel frequencies of the elderly group and the middle-aged/young group. Regarding household attributes, middle-aged/young people with a higher household income travel less frequently, whereas the case is completely the opposite for the elderly. The number of cars has a significant positive effect only on the middle-aged/young group and has no effect on the elderly group. The number 
of bicycles has a significant positive effect on the travel frequency of both the elderly group and the middle-aged/young group. The elderly with more members in the household, namely, a larger household size, have a higher travel frequency. In terms of personal attributes, gender has a significant negative effect on the elderly's travel frequency; that is, women travel less than men. Employment status has a significant positive effect on the travel frequency of middle-aged/young travelers. Monthly tickets have a significant negative effect on the travel frequencies of both the elderly group and the middle-aged/young group. Regarding travel attributes, travel distance and travel duration have a significant negative effect on the two groups' travel frequencies.

(3) Due to the level of regional economic development and the proportion of women, the mobility of the elderly in some developed countries is much higher than that of the elderly in Beijing. However, Based on the population structure of Beijing, those who are currently middle-aged/young people will become a "new generation" of the elderly in the near future, and they will have accumulated a certain level of wealth in the process of the reform and opening up. Therefore, in the next few decades, the rate of car ownership among the elderly in Beijing will grow rapidly, which will bring the lack of sustainability of travel patterns, further will bring new challenges to policymakers and transport planning departments.

(4) For policymakers or transport planning departments, recognizing the regional difference in the elderly's behavioral characteristics can help in adopting travel demand management policies and measures according to local conditions. At present, the elderly in Beijing mainly travel by walking, supplemented by public transport. Therefore, we should further improve the pedestrian system and the comfort and security level of public transport. Simultaneously, we need to recognize that the "new generation" of the elderly in Beijing will have a rapidly increasing dependence on cars. As a result, from the perspective of traffic congestion management, combined with the factors that influence the elderly's travel frequency, the government should introduce corresponding measures to manage the elderly's cars.

Acknowledgments: The work was supported by the 60th China postdoctoral Science Foundation funded project (grant No. 2016M601045); Beijing Union University “New Starting Point" project "Research on the balance of Beijing-Tianjin-Hebei" "Green Innovation Industrial Park" (Sk10201503).

Author Contributions: Huapu Lu and Wenzhi Liu conceived and designed the experiments; Huapu Lu performed the experiments; Wenzhi Liu and Zhiyuan Sun analyzed the data; Zhiyuan Sun and Jing Liu contributed analysis tools; and Wenzhi Liu wrote the paper.

Conflicts of Interest: The authors declare no conflict of interest.

\section{References}

1. National Bureau of Statistics of China. Statistical Communique of the People's Republic of China on 2015 National Economic and Social Development. Available online: http:/ / www.stats.gov.cn/english/ pressrelease/201602/t20160229_1324019.html (accessed on 12 January 2017).

2. OECD Statistical Database. Available online: http://stats.oecd.org/ (accessed on 19 December 2016).

3. Netherlands Environmental Assessment Agency. VergrijzingenRuimte: Gevolgenvoor de Woningmarkt, Vrijetijdsbesteding, Mobiliteit en Regionale Economie; Planbureauvoor de Leefomgeving (PBL): The Hague, The Netherlands, 2013.

4. Liu, S. Research on the Impact of Population Aging in Beijing on the Consumption Structure; Beijing Jiaotong University: Beijing, China, 2016.

5. Harper, S. Economic and social implications of aging societies. Science 2014, 31, 587-591. [CrossRef] [PubMed]

6. Liu, W.; Zong, G.; Zhang, C. An integrated model of urban transportation and land use. J. Inn. Mong. Univ. (Nat. Sci. Ed.) 2013, 44, 212-218.

7. Arentze, T.A.; Timmermans, H.J.P.; Jorritsma, P.; OldeKalter, M.J.; Schoenmakers, A. More gray hair-but for whom? Scenario-based simulations of elderly activity travel patterns in 2020. Transportation 2008, 35, 613-627. [CrossRef]

8. Bocker, L.; Amen, P.; Helbich, M. Elderly travel frequencies and transport mode choices in Greater Rotterdam, the Netherlands. Transportation 2016. [CrossRef] 
9. McDonald, N.C. Children's mode choice for the school travel: The role of distance and school location in walking to school. Transportation 2008, 35, 23-35. [CrossRef]

10. Zong, G.; Liu, W.; Zhang, C. A household decision-based disaggregate mode choice model. J. Hunan Univ. (Nat. Sci. Ed.) 2013, 40, 100-103.

11. Oxley, J.; Whelan, M. It cannot be all about safety: the benefits of prolonged mobility. Traffic Inj. Prev. 2008, 9, 367-378. [CrossRef] [PubMed]

12. Mao, H. A Study on the Travel Characteristics of Chinese Urban Residents; Beijing University of Technology: Beijing, China, 2005.

13. Alsnih, R.; Hensher, D.A. The mobility and accessibility expectations of seniors in an aging population. Transp. Res. 2003, 37, 903-916. [CrossRef]

14. Currie, G.; Delbosc, A. Exploring public transport usage trends in an aging population. Transportation 2009, 37, 151-164. [CrossRef]

15. Donaghy, K.; Rudinger, G. Societal trends, mobility behavior and sustainable transport in Europe and North America. Transp. Rev. 2004, 24, 679-690. [CrossRef]

16. Sandra, R. Sustainability and automobility among the elderly: An international assessment. Transportation 2001, 28, 375-408.

17. Pa'ez, A.; Scott, D.; Potoglou, P.; Kanarogou, P.; Newbold, K.B. Elderly mobility: demographic and spatial analysis of travel making in the Hamilton CMA, Canada. Urban Stud. 2007, 44, 123-146. [CrossRef]

18. Baek, S.R.; Moudon, A.V.; Saelens, B.E. Comparisons of physical activity and walking between Korean immigrant and white women in King County, WA. J. Immigr. Minority Health 2016, 18, 1541-1546. [CrossRef] [PubMed]

19. Kim, S. Assessing mobility in an aging society: Personal and built environment factors associated with older people's subjective transportation deficiency in the US. Transp. Res. 2011, 14, 422-429. [CrossRef]

20. Kemperman, A.D.A.M.; Timmermans, H.J.P. Green spaces in the direct living environment and social contacts of the aging population. Landsc. Urban Plan 2014, 129, 44-54. [CrossRef]

21. Bocker, L.; Thorsson, S. Integrated weather effects on cycling shares, frequencies and durations in Rotterdam, the Netherlands. Weather Clim. Soc. 2014, 6, 468-481. [CrossRef]

22. Liu, W.; Tao, Q.; Lu, H. Niched genetic algorithm based disaggregate mode choice model. Int. J. Simul. Syst. Sci. Technol. 2016, 17, 80-85.

23. Ding, Y.; Lu, H.P.; Zhang, L. An analysis of activity time use on vehicle usage rationed days. Transportation 2016, 43, 145-158. [CrossRef]

24. Zhang, Y.; Yang, X. Household, personal and environmental correlates of rural elderly's cycling activity: evidence from Zhongshan metropolitan area, China. Sustainability 2014, 6, 3599-3614. [CrossRef]

25. Strawbridge, W.J.; Deleger, S. Physical activity reduces the risk of subsequent depression for older adults. Am. J. Epidemiol. 2002, 156, 328-334. [CrossRef] [PubMed]

26. Nobis, C.; Lenz, B. Gender Differences in Travel Patterns: Role of Employment Status and Household Structure. Available online: https: / / trid.trb.org/view.aspx?id=773080 (accessed on 25 February 2017).

27. Liu, Y.; Feng, Y. Simulating the impact of economic and environmental strategies on future urban growth scenarios in Ningbo, China. Sustainability 2016, 8, 1045. [CrossRef]

28. Pas, E.I. Intrapersonal variability and model goodness-of-fit. Transp. Res. 1987, 21, 431-438. [CrossRef]

29. Beijing Municipal Administration and Communications Card. Available online: https://baike.so.com/doc/ 6555194-6768943.html (accessed on 26 May 2017).

30. Gao, M. Discussion on metro ticket pricing and reform strategy-Take Beijing Subway for an example. Price Mon. 2014, 11, 53-67.

31. Colia, D.V.; Sharp, J.; Lee, G. The 2001 national household travel survey: A look into the travel patterns of older Americans. J. Saf. Res. 2003, 34, 461-470. [CrossRef]

32. Transport for London. 2014. Available online: https://tfl.gov.uk/info-for/media/press-releases/2014 (accessed on 15 May 2017).

33. U.S. Department of Transportation. Summary of Travel Trends: 2009 National Household Travel Survey. Available online: http:/ / nhts.ornl.gov/2009/pub/stt.pdf (accessed on 3 May 2017).

(C) 2017 by the authors. Licensee MDPI, Basel, Switzerland. This article is an open access article distributed under the terms and conditions of the Creative Commons Attribution (CC BY) license (http:/ / creativecommons.org/licenses/by/4.0/). 